\title{
Interactions between global processes and local health problems. A human ecology approach to health among indigenous groups in the Amazon
}

\author{
Interações entre processos globais e problemas \\ de saúde locais: uma abordagem ecossistêmica \\ à saúde de grupos indígenas na Amazônia
}

\footnotetext{
1 Iberoamerican Institute Göteborg University. Box 200 SE 40530 Göteborg, Sweden. majlis.foller@ibero.gu.se
}

\begin{abstract}
This article deals with methodological issues and how to link global processes - social and ecological - with environmental changes and human health in local communities. The discussion concerns how interdisciplinary approaches can help us find tools to develop new knowledge. Scientific knowledge and local knowledge are not seen as opposite epistemological forms, but as socially and culturally constructed. Power and social legitimacy have to be included when analyzing how to deal with the interaction between global processes and local environmental change and the health/disease interface.
\end{abstract}

Key words Human Ecology; Amazonian Ecosystem; South American Indians; Health

Resumo O artigo lida com questões metodológicas e relações entre processos globais - tanto sociais quanto ecológicos - e mudanças ambientais e sanitárias em comunidades locais. A autora discute como as abordagens interdisciplinares podem ajudar a encontrar instrumentos para desenvolver novas formas de conhecimento; defende que o conhecimento científico e o saber local não devem ser vistos como formas epistemológicas opostas, mas como construções sociais e culturais; e preconiza que o poder e a legitimidade social precisam ser incluídos quando se analisa como lidar com a interação entre processos globais, por um lado, e mudança ambiental local e processo saúdeldoença, pelo outro.

Palavras-chave Ecologia Humana; Ecossistema Amazônico; Índios Sul-Americanos; Saúde 


\section{Introduction}

This paper focuses on methodological approaches to global social and ecological processes and the interaction with and influence upon the human ecological health situation at the local community level. The local knowledge system is discussed as an institution existing at the community level, often referred to as a local episteme or local epistemology. Local knowledge as pertains to this article deals with human health issues, perception of nature, and local resource management. It is based on cultural norms, long-standing practice and experience, and societal conventions.

Within the social sciences, the globalization concept is used in various contexts, mostly relating to the spread of economic investment worldwide, trade relations, migration, and transmission of information through satellite television and Internet. In this article, globalization highlights how certain economic, political, and cultural global processes are involved in the production of communicable and emerging diseases, thereby becoming an integral part of the local sphere. In addition, today's industrialized world is resulting in global environmental changes, e.g., climate change, stratospheric ozone depletion, and loss of biodiversity. Such aspects are central to the discussion of epidemics and emerging diseases. The question is how to deal with the new world order within society, public health, and natural and social sciences.

Globalization is also viewed from a historical perspective, thus becoming part of world development, including colonial and postcolonial history. Post-colonial is seen as a historical condition, indicating that socioeconomic and political change occurred at the end of the colonial period, but that these processes continue and influence the current situation. Ecological history is part of this new understanding of the immense influence colonization had on the exchange of germs, seeds, and animals (Crosby, 1994). Alfred Crosby has shown how contact between Europe and the Americas during the 16th century involved a spread of European pathogens to New World populations which lacked immune defenses against this micro-world, a process he conceptualizes as "ecological imperialism" (1972, 1986). One example of a post-colonial perspective is the development of sugar plantations in Northeastern Brazil during the colonial period. The lack of cheap labor in the Americas contributed to the rise of the African slave trade and the consequent introduction of yellow fever and malaria into the New World. The spread of cholera in India, aided and abetted by manmade malnutrition and famine, is another issue related to the colonial period. Such examples elucidate the social and political forces fostering the spread of epidemic disease throughout the colonial period, illustrating that disease is not something "natural". Sheldon Watts develops this position by stating that disease is always socially constructed, based on moral, racial, and cultural prejudices, as opposed to the modern understanding of infections and epidemics (Watts, 1997). He uses the "disease construct" concept, which I find useful in a diachronic perspective, as in the examples above, but also in a synchronic perspective, to show interactions over space. Human activities taking place in one part of the planet influence the disease pattern of distant populations.

This paper's hypothesis is that globality and modernity should be seen as integrated parts of the local sphere, i.e., emphasizing the interface between global social and ecological changes (interpreted and explained in the global scientific society) and the community, where diseases affect people and where there is the potential for local health knowledge to deal with them. This field of research will be analyzed, stressing the role of crossing disciplinary borders. The challenge in viewing global as part of local is that it questions the conventional distinctions in social sciences between "macro" and "micro", between macro-socioeconomic processes and events and interactions in the community, the practice of everyday life. The community can be the victim of global development processes, but it can also be a unit actively involved in changing living conditions. Different boundaries between global and local are dissolved, and the meaning of this process is developed.

\section{Background}

The following discussion reflects on and responds to the International Meeting "An Ecosystem Approach to Human Health: Communicable and Emerging Diseases" held in Rio de Janeiro in November 1999. The main organizer was the International Development Research Centre (IDRC). According to the background documents for the IDRC workshop, the ecosystem approach to human health should accommodate both basic scientific research and participatory grassroots activity, both reoriented to a systems view of the world (Waltner-Toews, 1999). From this perspective, which can be called applied research or participatory action 
research (PAR), one central question is how it is possible for policy-makers and practitioners to think more creatively about the development of an ecosystem approach to health and disease. Another issue I see as crucial for dealing with community health issues is the search for a dialogue between local communities and central decision-makers with a view towards improving health conditions. I also agree on the emphasis concerning the connection between research and action, which is accentuated in the ecosystem approach. New links between scientists, authorities at different levels, and practitioners and community members need to be established in order to achieve sustainable and healthy development. But each level is distinct. Both the integrity of each discipline and a common language crossing institutional boundaries have to be stressed. A broad interdisciplinary approach is thus necessary.

\section{Purposes and methods}

The methodological issues deal with the significance (for the formation of knowledge) of finding interactions between global and local processes. A research field defined as "human ecology and health" will be described (Follér \& Hansson, 1996). It is broader in its scope than an ecosystem approach, as defined by David Waltner-Toews (1999) and others. It deals with human health in a comprehensive and interdisciplinary way and includes three levels. These are ecological perspectives, consideration of the global context, and attention to the health impacts of major cultural and social changes. Within today's globalization, everything is connected to everything else in one way or another. But, and this is crucial, some aspects are more connected to the "environment/health" context than others. The purpose of focusing on this interplay and holding the above-mentioned levels together is:

- to elucidate interdisciplinary research methods, emphasizing the interface between global science and local knowledge systems and questioning the dichotomy between global and local knowledge;

- to find new forms for knowledge formation or research strategies, involving a combination of anthropological methods (illness narratives, close reading) and natural and social sciences (macro and micro), public health, and the knowledge of those affected by development interventions; and

- to establish a conceptual framework based on this new knowledge formation.
The interface between global processes producing diseases and how such diseases affect people's daily lives is part of the knowledge within various academic disciplines, which seldom communicate amongst each other. Global ecological and social processes related to communicable and emerging diseases affect people on a regional and local level. This will be discussed on a general theoretical level by analyzing the interplay between systems on different levels, macro as well as micro. On all levels of society there are power relations and a variation of knowledge due to factors like age, gender, kinship, religion, and other social and cultural personal experiences. Methodologically, local narrative forms of analyses are emphasized without ignoring the repercussions of macro processes in grasping and encompassing everyday social life. The research strategy is to conduct local studies with the researcher's presence in the community (some form of action research), communication, and interviews aimed at understanding and structuring the social order and finding tools for the interplay between local and global.

The paper provides examples from my own research among the Shipibo-Conibo in the Amazonian region of Peru. That study shows how people in the community were affected by a cholera epidemic and how they dealt with it within the family and community. Since 1983 a local health project, Ametra (Application of Traditional Medicine), has conducted health education in the villages (Cárdenas, 1989; Follér, 1995, 1990). The point of departure for the health courses is the contemporary perception of health and disease among the Shipibo-Conibo. Ametra explicitly aims to use the most appropriate treatment for the disease, whether biomedicine or ethnomedicine. A question raised in my research was how people applied this knowledge when the cholera epidemic appeared. The next step was to examine what happened when external actors like the regional health authorities and an international organization, Doctors without Borders, intervened (Follér \& Garrett, 1996). The research method was to collect "illness narratives" from community members and conduct interviews with the organizations and institutions mentioned above.

\section{Human ecology and health in relation to other disciplines}

As an academic field, "human ecology and health" has ties with several other areas, with which it has both commonalties and differ- 
ences. These include environmental health, public health, epidemiology, medical anthropology in ecological perspective, medical sociology, and social medicine. However, this does not comprise an exhaustive list of disciplines and special fields that address the interactions between human beings, their environment, and the effects on health seen within a global context. The complexity of the subject and the diversity of existing and emerging perspectives can be seen in the many publications in ethnomedicine, medical geography, geomedicine, clinical ecology, human biology, medical ecology, ecosystem health, and ecosystem approach to health (Follér et al., 1996). A research review addressing many aspects of current and emerging infectious diseases gives an insight into the fragmentation of the literature in various research areas and disciplines (Chan et al., 1999).

Human ecology and health is an interdisciplinary approach which shares with some other disciplines the view that humans are physical beings seen as part of the ecosystem and that they can be harmed by things in that ecosystem, including threats from human society itself. With anthropological disciplines, especially sub-disciplines such as ecological anthropology and some parts of medical anthropology, it shares a view of humans as social beings whose adaptation to the environment and health status are tied to culture. What is unique about the three characteristics defining human ecology and health is the ecological perspective towards human health, its perception of local health patterns within a global context, including their connection to worldwide trends in population growth, resource depletion, and environmental deterioration, and special attention to the health implications of cultural and social change, particularly to modernization, globalization, urbanization, increasing socioeconomic inequality, and Western-style economic development.

The ecosystem approach, as expressed in various IDRC documents, is explicit in its statement that the research must be applied research, with a systemic approach. The human ecology and health field is distinguished as having a more qualitative method than a systemic approach. Another difference is that human ecology and health has explicit interdisciplinary intentions, going beyond multidisciplinary projects in which the various researchers invest their respective world views in the project. The interdisciplinary approach strives towards a common world view, language, and conceptual framework among the participat- ing researchers, in this case concerning issues related to environmental changes and human health.

\section{The meaning of global environmental change}

The global environmental changes discussed in this article are those produced by human activities. There are also what can be called "natural" (ecological and biological) changes, but human-induced climate change and the cultural dimension of global environmental change will be highlighted in this paper. Social dimensions of resource use, environmental security, and sustainable development are all issues dealt with by the social sciences, but the human (individual and social) institutions driving the forces resulting in global environmental change are largely not integrated in a systematic way. Population change, economic growth, technological change, political-economic institutions, and people's attitudes and beliefs always take place within a cultural context. Various human driving forces act in a certain direction and result in ecological changes on local as well as global levels. Epidemics of communicable and emerging diseases occur at the interface between the cultural context and global environmental changes.

The importance of local and space-specific variables are emphasized. These can be expressed as the community's understanding of ecological changes. People's perception of how the local environment relates to certain diseases is another concern. This dimension is often a "missing link" when research on cooperation between global and local processes is undertaken. Even in an ecosystem approach, as presented in various documents, local knowledge systems are not sufficiently emphasized. These factors are not stressed sufficiently either by public health authorities or within science. The gap is still broad between the two cultures, natural sciences and humanities/social sciences. What C. P. Snow (1969) said in the 1960s still holds, that there is a long way to go until natural, social, and medical scientists see each other as equal partners and attempt to find a common language.

Fields of knowledge should vary, and it is important with pluralism in perspectives, methods, and theoretical approaches that each discipline has its distinctive character. But to solve a health problem related to emerging and/or communicable disease in a community, region, or state, the research group has to 
find a common world view and language so that they can communicate both amongst themselves and with those outside the academic world.

Humans cause environmental change, but as soon as the effect on the ecosystems appears, the environmental changes have an effect on the human health. Amazonian deforestation is affected by cultural, political, demographic, and economic factors. And there are synergisms - in this case between rainforest destruction, loss of biodiversity, and global climate change - with potential impact on health (Dobson \& Carper, 1994).

\section{Globalization and the life support system}

Within the framework of sustainable development, human populations face a new type of threat to health, perhaps even to longer-term survival. By damaging the planet's life support system, energy-intensive technology and consumption are overloading Earth's capacity to absorb, replenish, and repair (McMichael, 1995). Anthropogenic damage to the biosphere has potentially important implications for health. The underlying processes are global in scale, and the natural systems affected are part of earth's life supporting infrastructure (Haines et al., 1994:31). A life support system is any natural or human-engineered system that furthers the life of the biosphere in a sustainable fashion. The fundamental attribute of life support systems is that together they provide all of the sustained requirements for continuance of life. These needs go far beyond biological requirements. Thus life support systems encompass natural environmental systems as well as ancillary social systems required to foster societal harmony, security, nutrition, medical care, economic standards, and the development of new technology. The one common thread in all of these systems is that they operate in partnership with the conservation of global natural resources.

A prominent feature in today's global world is the increasing scale of human impact on Earth's life support systems. We are confronted with several warnings concerning the planet's growing fragility. The World Commission on Environment and Development/Our Common Future (1987), often called the Brundtland Report, was one step. It was followed by the United Nations Conference on Environment and Development (the Earth Summit) in Rio de Janeiro in 1992, and many more reports and conferences followed in the wake of these events (WCED, 1987). They have all raised awareness concerning the state of the planet and contributed to the discussion of sustainable development. Yet the link between human health and the ecosystem is not explicit in these documents.

One of the documents from the Earth Summit/Agenda 21 states:

"The growth of world population and production combined with unsustainable consumption patterns places increasingly severe stress on the 'life supporting' capacities of our planet. These interactive processes affect the use of land, water, air, energy, and other resources." (UN, 1992:Section 5.3.).

We can add that these processes also affect human health. There is a connection between global climate change and human health on many different levels in society, probably with significant loss of life. We can expect the process to become more widespread and unpredictable in the near future. We know that there is a relation between climate change and vector-borne diseases (Nicholls, 1994; Rogers \& Packer, 1994; Martens, 1998; Martens et al., 1995) and between climate change and food security (Parry \& Rosenzweig, 1994; Ruttan et al., 1994). We can also find connections between globalization and the sustainability of human health, in addition to other forms of human impact on Earth's natural biophysical systems, including the climate system, the stratospheric ozone, biodiversity, terrestrial and marine food-producing ecosystems and the great water, nitrogen, and sulfur cycles. These systems sustain our planet's life supporting capacities and therefore have direct and future implications for human health (McMichael, 1995; Last, 1998).

The effects can be divided into two categories: direct and indirect. Direct effects result from immediate exposure to weather extremes caused by climate change, e.g., heat stroke, hypothermia and deaths or injuries resulting from tidal waves, floods, and hurricanes. Indirect effects result from subsequent changes in environment and ecosystems, e.g., the spread of vector-borne diseases into new areas, nutritional problems resulting from crop failure, diseases spread by algal blooms in warming seas, and even mental health problems which may result from social and political dislocation (Kingsnorth, 1999). 


\section{The connection between the global and local levels on health issues in social sciences}

Today's environmental problems, which are linked to local health problems, have a global connection. This creates a tension between the need for governance on different levels (global, national, regional, and local) to take measures for globally and locally sustainable environmental security. The first step is to demonstrate the connection between global environmental change, e.g., climate change, biodiversity, stratospheric ozone depletion, and air pollution (tropospheric ozone highs), because these relations are naturally very complex and nonlinear. In order to find methods to show the connection we need to develop a knowledge whose scope falls outside the conventional field of single disciplines. Such knowledge must be inter- or transdisciplinary, a combination of scientific knowledge and knowledge produced within society at large. The question will be how to investigate these connections and how to apply the new knowledge, following the Brundtland Commission guidelines and the Rio Conference Agenda 21 document, with the aim of better health in the communities.

One approach begins with contemporary global development focusing on global ecological changes and an analysis of the consequences of the changes described above on human health. Some of the threats to human health resulting from global climate change involve a greenhouse-related increase in heat waves, drought, and floods, besides stratospheric ozone layer destruction with the risks of skin cancer or reduced immune defenses. People in urban areas today are more aware of the damage caused by ultraviolet radiation. Studies on the relationship between air conditioning and deaths during heat waves have also been undertaken to encourage people to stay indoors, when such conditions occur, with the air conditioning turned on.

Poor and marginalized people in rural areas of Third World countries are also affected by these global ecological processes, but information from national and regional health authorities is generally not relevant or accessible to them. Questions such as what health care institutions we need in the future to deal with the new global health threats have to be raised. Other issues involve which ecological and health knowledge is of importance to the communities in order to implement a policy to protect people equitably (urban/rural, poor/rich, and regardless of ethnicity).
The other approach begins with the local reality. According to this perspective, health problems, e.g., malaria, cholera, or HIV/AIDS, already exist and have to be handled mainly from local actors' accumulated experience, but in cooperation with regional health authorities and areas of science. Such knowledge is anthropological with regard to the functioning of social institutions, local management, power hierarchies, culture, behavior, and local knowledge systems, especially local health and ecological knowledge.

Local knowledge has been gained through accumulated experience and negotiation with other knowledge systems. It is not a closed system, but communicates continuously with other systems. We must be aware of the existing power hierarchical structures in society, especially within scientific knowledge. The challenge with an attempt at a bottom-up approach is to find solutions for the community level that are also sustainable at the regional and global levels. This means that community members have to be involved in defining both the problems and solutions. A central issue in this research is to view local knowledge as a dynamic process, just like other forms of knowledge. New local knowledge is created in the communities, and there has been a missing link between local health epistemology and social science. Rather often, local knowledge is seen as part of the health problem rather than part of the solution. Global science and local knowledge are two fields of knowledge with almost no inter-communication. How can scientists, development experts, and regional health authorities find an operational research link between remote sensing (satellite monitoring) and close reading (anthropological fieldwork) with an open dialogue to the surrounding society?

\section{Local knowledge systems}

Local knowledge, as discussed above, is an informal institution including knowledge, technology, practices, beliefs, and value systems. It is developed over time, based on centuries of living close to nature. This institution represents hundreds or thousands of years of cultural experience with forest dynamics, animals, plants, and ecosystems (the significance for growing urban communities is beyond the scope of this article). Societies, cultures, and knowledge systems are never closed units, but exist in cooperation with adjacent knowledge systems that can be local indigenous knowledge systems or folk and scientific knowledge. 
Local knowledge systems or thoughts are complex systematic bodies of knowledge that categorize and describe relationships between humans and their environment. They are communicated through symbols, language, rituals, songs, music, and narratives. Local knowledge and scientific or modern knowledge are sometimes approached as if they were complementary or opposite. What we find in reality has to do with hierarchical structures, where scientific knowledge is seen as superior to all other forms of knowledge. This has to do with power and the precedence of interpretation by science, a form of ethnocentrism. It is also referred to as "scientism", according to which, knowledge pertaining to all other cultures should be evaluated from the scientific standpoint. During the colonial period the educational system was based on Western scientific knowledge, a situation persisting even today in the former colonies. Educational and health authorities, missionaries from European and North American churches, and colonial administrators have often undermined and degraded local knowledge within respective fields. Local knowledge was and is seen as the scapegoat for underdevelopment (Nygren, 1999).

Cross-cultural comparisons of knowledge and technology systems have been performed within anthropology, theory of science, and other social sciences. The approach during the 1970s was ethnocentric. The basis was Western scientific "rationality", and other knowledge systems were valued and evaluated according to such criteria. Indigenous knowledge systems were regarded as closed systems and scientific knowledge as an open system. These distinctions between knowledge systems have their basis in a view of where knowledge is believed to be embedded in societies. Western societies are seen as progressive, with emphasis on change and growth. The idea of rationality is linked to the growth of knowledge. Yesterday's knowledge, especially within sciences and in the medical field, is seen as obsolete, irrelevant, and worthless. There is an optimism concerning the knowledge we are expected to have tomorrow and its power to solve problems pertaining to the environment, disease, and life itself (e.g., the Human Genome Project).

Local knowledge is not a universal solution for progress and development in rural communities in Africa, Asia, and Latin America, nor a panacea for sustainability. Local and scientific knowledge systems both have their shortcomings. There are, as mentioned earlier, power relations between scientific and local knowledge. But it should also be stressed that all societies have individual members with different forms of knowledge, depending on varied practices, skills, and understandings, and that all knowledge is valued differently. Such variation can be between men and women or young and old, for example, or between specialized knowledge (such as the knowledge of a traditional midwife, a medicine man, or other special knowledge) and the majority of the people in a community. Individual knowledge within the fields of health/healing, agriculture, fishing, or hunting, as some form of professional knowledge, has some collective basis. This dimension gives the knowledge system a coherent, connectable “wholeness". However, as stressed earlier, no knowledge system exists in isolation. Globalization is changing these boundaries, with television, Internet, and more interaction between people through travel and trade. Anja Nygren defines this as "situated knowledge", one that is simultaneously local and global, a perspective that "re-maps" the fixed boundaries between rational and practical, modern and traditional (Nygren, 1999). But as the concept itself says, local knowledge is partly space-specific, thanks to its "localness". Even if the definition of local knowledge as situated knowledge is a fact, it is still not a simple "either/or" knowledge. Knowledge is culturally constructed. My own experience with the Shipibo-Conibo is that they are very open to integrating knowledge from the mestizo society. Practices and therapies from the regional biomedical sector are also accepted or rejected, and alternative medicine of an Oriental origin, spread through journals and pamphlets, is often encompassed by or integrated into ethnomedical knowledge. But the basis is in some way culture-specific and has a particularity, which I see as important to articulate and legitimize. What has to be stressed in this contribution is that all knowledge is developed in a cultural and social context and therefore not easily transferred to new settings. Still, as will be discussed in relation to the ShipiboConibo case study, space-specific knowledge can be used as exempla and thereby offer valuable explanations.

Portraying scientific knowledge as the opposite of local knowledge is a form of dichotomization, a common feature in Western thinking. This approach to indigenous peoples' knowledge and their contribution to a sustainable future have been partially questioned and replaced by a new model (Nygren, 1999). The idea that scientific knowledge often has its basis in knowledge belonging to and developed by people living in what is called the periphery, i.e., rural Africa, Asia, and Latin America, is in- 
creasingly acknowledged in scientific circles. In these local settings, health-related knowledge, e.g., which plants to use for certain ailments and specific diseases, has its own rationality. Technology related to farming, irrigation, and pest control and how to treat the environment for the survival of the community often has its origin among people living in local communities and is frequently efficient (e.g. Ford, 1971; Richards, 1985; Balick et al., 1996). The idea that scientific knowledge and modern technology are part of today's ecological problems and diseases (the ones we refer to as "diseases and epidemics of civilization") must be taken into consideration when discussing what kind of knowledge we propose for a sustainable future.

\section{Global changes and human health: the example of cholera}

Through a human ecology and health approach the three aspects - the ecological perspective, the global context, and social change - will be elucidated to better understand emerging and reemerging and epidemic diseases. Not only are vector-borne diseases like yellow fever, dengue, and malaria becoming more common in some tropical areas (both rural and urban), but also age-old infectious/contagious diseases like cholera as well. In Latin America, cholera reemerged in 1991 after a 100-year absence. Infectious diseases have had an immense effect on Latin American history, including the demography, ecology, disease patterns, and cultural development (Crosby, 1986, 1994). The history of cholera is associated with trade caravans, migration, and refugee camps. It also shows a remarkably strong association with water and the sea (Colwell, 1996). Cholera is also associated with poverty, poor sanitation, and polluted inland waters, and new research indicates that it can also be harbored in marine plankton. Paul Epstein raises evidence of the relationship between climate change and health issues and indicates that algal blooms were the original cause of the cholera epidemic when the seventh pandemic struck Latin America in 1991 (Epstein, 1993, 1999).

Peru was first hit by the cholera epidemic in January 1991. It quickly spread across Latin America, killing over 5,000 people in eighteen months. There were 600,000 cases from 20 countries, and in many scientific articles the outbreak has been linked to global climate change and the warmer waters of El Niño (Epstein, 1999; Kingsnorth, 1999). There are sever- al discussions on the timing and outbreak between the El Niño phenomenon and the cholera outbreak in Peru. There is also the discussion as to whether 1990-91 was a real El Niño phenomenon or a post-construct. The first cases in Peru were among fishermen and sailors. These appeared in the port of Chancay, north of Lima, and a few days later cases were reported from Chimbote, several hundred kilometers to the north along the coast. In early February new cases were reported along the coast. The first reports indicated that the original source was a boat arriving in the port of Lima from a cholera area, unloading ballast. This is part of the truth, but other social and ecological conditions must be favorable in order for an epidemic to spread.

After the first reports from the coast, the epidemic spread rapidly across the country and over the Andes. By March/April that same year the disease had reached the Amazon region and also neighboring countries in Latin America. The connection between the cholera vibrio and the algae is that the plankton blooms were more intense during this period of the year due to climatic events related to El Niño. The situation can be characterized as presenting higher than normal rainfall, with an influx of nutrients from land and warm sea surface temperatures (Colwell, 1996; Epstein, 1993, 1999). Another ecological/biological factor is that the El Tor cholera biotype, the actual toxigenic vibrio, persists better than the classical biotype in the environment.

As indicated above, there are several scientific fields, including ecology (focusing on climate and water), microbiology (vibrio), and social sciences (poverty, education, and other risk factors) attempting to explain the origin and spread of the cholera epidemic. Other forms of scientific knowledge are also needed to create a more holistic approach to combating the increased burden of emerging infectious diseases. They have to do with the types of water that are ecologically suitable for the pathogen's survival during intervals between epidemics and where the respective bodies of waters are located. The vibrio's geographical location and ecology require other specialties for their elucidation. Vibrio cholerae ecology, like that of all other microorganisms, depends on environmental abiotic and biotic factors that are relevant to the microbe's survival (Borroto, 1997). Our understanding of the epidemic also depends on the crucial link between the microorganism, the human host, and their environment.

As been demonstrated above, cooperation between the natural and social sciences is a 
complex epistemological process. Starting from a macro-perspective, algal blooms and the amount and spread of phytoplankton and zooplankton can be measured by satellite imagery. A tricky methodological problem is to link satellite imagery with early health warning systems based on climate forecasting and remote sensing, traversing and cooperating with various natural scientific disciplines and local anthropological methods such as interviews and collecting illness narratives. Prevention of emerging epidemics can only be possible if new epistemological and methodological strategies are established to unveil the underlying social and environmental causes, trying to find accepted forms of intervention and an understanding of the construction of local epistemology or situated knowledge. It is necessary to cross academic disciplines with interdisciplinary projects, with the will to find a common problem orientation, while taking local knowledge into consideration.

\section{Globalization and the cholera epidemic}

The preceding section was an attempt to briefly trace the connection between global environmental change and the cholera epidemic. The main influences from social globalization, besides transnational economic transactions and the flow of information, are new mobility patterns. Without today's international maritime and airborne trade of goods and the increased mobility of human beings, a historically unique event, epidemics could not spread as fast as they do today. It is the lifestyle of people living far from the indigenous peoples of the Amazon, for example, that connects the global and the local in a unilinear fashion. This means that different ecological, social, and cultural boundaries are dissolved between the global and the local levels. The spread of the cholera vibrio knows no geographic boundaries. Knowledge on ecological and health issues for cholera prevention and cure is a broad and fragmented field in society and science. It exists on a global level in the WHO member health institutions, through national health ministries and down to the regional and local levels, which employ an over-arching biomedical paradigm. On the local level this may display a great epistemological variety, depending on the cultural context. But the process is united through a scientific framework with a single view of health and disease as primarily medical problems. The biomedical paradigm often excludes the local and specific socioeconomic, ecological, and cultur- al aspects and therefore hampers a grasp of the problems as they are perceived in the community. A more holistic approach including ecological and cultural aspects should be advocated for long-range sustainable development.

Even if, theoretically, everyone is susceptible to cholera, the "natural" victims are the poor. Cholera can therefore be defined as a disease of "others", contextualized and characterized as a so-called "tropical disease". The "educated", urban middle and upper classes isolated themselves from the poor in Latin America during the epidemic. This is the social construction of disease or "disease construct" as mentioned earlier (Watts, 1997). Values, ethical imperatives, and ethnic prejudices influenced the spread of cholera. Drought in Africa and cholera in India are other examples. Refugee camps in Rwanda and other war-stricken parts of the world are another situation where people are forced to leave their homes and move to makeshift camps. These examples show that there is not a linear climatic cause and effect relation. Natural catastrophes like Hurricane Mitch and the 1991 cholera epidemic in Latin America both had strong socioeconomic implications regarding who in society was exposed to the disasters.

The last decade has shown that extreme weather events like heavy rainfall, heat waves, and extended droughts have a profound impact on public health, particularly where poor people lack proper sanitation, water supply, and health care facilities (World Disaster Report, 1998). Social institutions and organizations and people's culture are an integral part of this environment. Differences in human social organizations have affected epidemic disease patterns of through time (Newson, 1998). A holistic approach, which contextualizes the historical and geographical aspects through trajectories of biological and social changes, must take the following issues into consideration: parasite and host biology, disease transmission patterns, and characteristics of the affected human society (Newson, 1998:42). How cholera spreads in a given area depends on all these factors, including social and cultural dimensions. Hence the significance of the local social context which ones elucidates by participatory observation, interviews, and ethnomethodology (ethnobotany, illness narratives) to understand the origins, spread, and impact of epidemic diseases, in comparison with information provided from the global perspective, e.g., through satellite imagery.

There are two simultaneous global components, environmental and socioeconomic. From 
an ecological point of view, climate constrains both the range of many infectious diseases and the timing and intensity of outbreaks (Haines et al., 1994; McMichael, 1995). However, the opportunity to survive disasters and epidemics has socioeconomic dimensions.

\section{A case study: illness narratives among the Shipibo-Conibo}

In April 1991, cholera spread to the Amazon region inhabited by the Shipibo-Conibo. By August that same year, about 250 individuals had died out of a population of 30,000. In 1993 and 1994 I conducted field research on the group's first encounter with cholera. I worked in Yarinacocha, with its sizable urbanized ShipiboConibo population, in the vicinity of Pucallpa, the second largest urban area in the Peruvian jungle. I also conducted interviews in several small Shipibo-Conibo villages (comunidades nativas) along the rivers and lakes. I will focus here on the issue of how human ecological factors related to mobility, changes in subsistence patterns, and education were involved in the epidemic. The methodology centered on illness narratives from individuals affected by the epidemic or those caring for them in their household. They were asked to report their perception of the causes, process, and treatment of cholera drawn from their own experiences.

The spread of cholera among the ShipiboConibo was facilitated by various human ecological factors arising from an increased interconnectedness with the surrounding society and accompanying social and cultural changes, such as mobility, modernization, and the shift to urban settings such as Pucallpa and Yarinacocha. The youth had increasingly enrolled in urban schools, and the women were selling their handicrafts to tourists. The men were also traveling outside the villages to work in logging, harvesting coca leaves, and oil prospecting activities.

When the epidemic started, the ShipiboConibo had never heard of cholera and therefore had no concept of it. It did not exist in their own language, and was seen as something coming from far away, something "alien", belonging to "others". They had problems classifying it in their local epistemology and thus understanding it within their cultural context. A process of "negotiation" began in order to incorporate different aspects of the epidemic into their cosmology and to form new knowledge, which was integrated into their local or situated knowledge. This process involved ne- gotiations regarding the cause of cholera and how it could be prevented and cured. Negotiations occurred between different bearers of knowledge, e.g., women as primary sources of everyday health knowledge and medicine men with their shamanistic and healing knowledge, including medicinal herbs. Other groups were the local primary health workers, Western medical doctors, and visiting medical brigades. The illness narrative method illustrates how knowledge is created through negotiation. Although the biomedical paradigm and local health knowledge are epistemologically distinct in their perception of health/illness and the therapies they employ, partial integration between the systems occurred. An interface was created by which ideas and information could be exchanged, certain concepts and practices rejected, and others borrowed and integrated.

Negotiation regarding the etiology of cholera was never problematic. The origin of cholera was perceived quite uniformly by the various social actors. I was informed that cholera is a contagious disease caused by microbes spread through unclean air, water, and food. There was a widespread awareness that risk of infection could be reduced by avoiding contaminated river water and always boiling water used for cooking and drinking. It was mentioned that people who neglected these precautionary measures were more easily infected and that people who did not boil their water (while traveling, for example) were at risk (Follér \& Garrett, 1996).

This description of cholera, including how it is transmitted and how chances of infection can be reduced through hygienic measures, was accepted by the Shipibo-Conibo. A massive campaign by the Peruvian national health authorities in which information was distributed through lectures, brochures, and radio was launched in the initial stage of the epidemic. The Shipibo-Conibo found the information important, accepted it, and integrated it into their strategy for handling the epidemic. Of course, there were also individual, idiosyncratic descriptions of the disease and explanations of why some people died of cholera while others did not, such as "it was not my turn yet" or "some people are more resistant". I had previously studied what can be described as their ethnomedicine with explanations of illnesses in their cultural categories, such as cupia, mal aire, and susto, but the origin of cholera was never categorized in these terms (Follér, 1990). A more elaborate version of my cholera case study is described in Follér \& Garrett (1996). 


\section{Conclusions}

The aim of this article has been to demonstrate the connection between global ecological and social processes related to infectious and emerging diseases, how they interact with local communities, and how this can be dealt with epistemologically. Issues such as what we can learn from taking local health knowledge seriously through collecting illness narratives are accentuated.

The point of collecting illness narratives is that they can serve powerful educational functions. They can be a first step of understanding the world from the point of view of the other by constructing exempla (Nussbaum, 1996). They are particularistic, rather than abstract or detached. They can offer explanation in a powerful fashion, not unlike scientific explanation. Local forms of knowledge and organization are rooted in everyday life experiences and tell us something of the understanding of reality by men and women living in the community. But again I stress that the two extremes should be avoided: on the one hand, the populist and romantic view of "the noble ecological savage" living in harmony with nature, whereby one suggests that today's ecological and health problems could be solved with their practical wisdom (Follér, 1997; Nygren, 1999); on the other, the notion that there is only one rational knowledge (scientific) and only one medical paradigm (biomedical). The underlying assumption in the latter epistemology is that in the near future it will solve global ecological problems and contain emerging diseases. Therefore, a respectful insight that current Westernized lifestyle, science, and technology are part of today's health and ecological problems seems reasonable. All forms of knowledge are socially and culturally constructed, and the common Western epistemological differences between local knowledge and scientific knowledge must therefore be questioned. Processes in society that legitimize certain knowledge and power hierarchies should be included in

\section{Acknowledgments}

I wish to thank IDRC for inviting me to the international workshop on "An Ecosystem Approach to Human Health: Communicable and Emerging Diseases" at the Escola Nacional de Saúde Pública in Rio de Janeiro. Special thanks to Magnus Bergvalls Foundation, Stockholm, Sweden, for providing economic support for my library research at ENSP/FIOCRUZ in Rio de Janeiro. the analysis of the prevalent Cartesian dichotomy model (Nygren, 1999). Illness narratives as a methodological and epistemological "missing link" might elucidate how to:

- find specific and local health effects connected to ecological issues and changes;

- understand how these health problems are explained and interpreted at the local level; and - discover how regional health authorities, international NGOs, and local NGOs are acting and what their intervention means.

The goal is to strive towards knowledge of how we on a scientific level and in international organizations can deal with epidemics, like that of cholera, to prevent global epidemics. On a local level, the goal is to find ways to prevent new outbreaks in parts of the world that are now endemic. To achieve long-range sustainable development, preventive measures, whether medical or environmental, must be firmly rooted at the local level. In this article I have stressed that many disciplines need to contribute, including ecology, microbiology, marine biology, epidemiology, and medicine, but also anthropology and human ecology, to link the societal aspects of epidemics to the disease pattern. But in order to achieve these long-term solutions, the community must be actively involved in the process from the initial planning and intervention stages onwards. Some central aspects are empowerment, institutional capacity, risk perception, and formation of knowledge. To achieve sustainable development of change in the community, local and scientific epistemology are affected. Changes in communities vary in accordance with culture, power, and gender. But again, to find the interface between global science and local knowledge, it is central to develop a common image of the problem.

"To give meaning to our science, we have to depart from science, and interpret what we have done in terms which have meaning to those who are the subject of study, as well as to those by whom or for whom the study was done" (Little, 1998:1144).

\section{References}

BALICK, M. J.; ELISABETSKY, E. \& LAIRD, S. A., 1996. Medicinal Resources of the Tropical Forest: Biodiversity and its Importance to Human Health. New York: Columbia University Press.

BORROTO, R. J., 1997. Ecology of Vibrion cholerae serogroup 01 in aquatic environments. Pan American Journal of Public Health, 1:1:3-8.

CARDENAS, T. C., 1989. Los Unaya y su Mundo, Aproximación al Sistema Médico de los Shipibo- 
Conibo del Río Ucayali. Lima: Instituto Indigenista Peruano.

CHAN, N. Y.; EBI, K. L.; SMITH, F.; WILSON, T. F. \& SMITH, A. E., 1999. An integrated assessment framework for climate change and infectious diseases. Environmental Health Perspectives, 107:329-337.

COLWELL, R., 1996. Global climate and infectious disease: The cholera paradigm. Science, 274:2025-2031.

CROSBY, A. W., 1972. The Colombian Exchange: Biological and Cultural Consequences of 1492. Westport: Greenwood Press.

CROSBY, A. W., 1986. Ecological Imperialism: The Biological Expansion of Europe, 900-1900. Cambridge: Cambridge University Press.

CROSBY, A. W., 1994. Germs, Seeds \& Animals. Studies in Ecological History. New York: M. E. Sharpe.

DOBSON, A. \& CARPER, R., 1994. Biodiversity. In: Health and Climate Change (D. Sharp, ed.), pp. 69, London: The Lancet.

EPSTEIN, P. R., 1993. Algal blooms in the spread and persistence of cholera. Biosystems, 31:209-221.

EPSTEIN, P. R., 1995. Emerging diseases and ecosystem instability: New threats to public health. American Journal of Public Health, 85:168-172.

EPSTEIN, P. R., 1999. Climate and health. Science, 285 347-348.

FOLLÉR, M. A., 1990. Environmental Changes and Human Health. A Study among the Shipibo-Conibo in Eastern Peru. Göteborg: Göteborg University.

FOLLÉR, M. A., 1995. Future health of indigenous people: A human ecology view and the case of the Amazonian Shipibo-Conibo. Futures, 27:1005-1023.

FOLLÉR, M. A., 1997. Protecting nature in Amazonia. Local knowledge as a counterpoint to globalisation. In: Cross-Cultural Protection of Nature and the Environment (F. Arler \& I. Svennevig, org.), pp. 134-147, Odense: Odense University Press.

FOLLÉR, M. A. \& GARRETT, M. J., 1996. Modernization, health and local knowledge: The case of the cholera epidemic among the Shipibo-Conibo in Eastern Peru. In: Human Ecology and Health. Adaptation to a Changing World (M. A. Follér \& L. O. Hansson, org.), pp. 135-166, Göteborg: Göteborg University.

FOLLÉR, M. A.; GARRETT, M. J. \& HANSSON, L. O., 1996. Human ecology and health: Its development and central themes. In: Human Ecology and Health. Adaptation to a Changing World (M. A. Follér \& L. O. Hansson, org.), pp. 7-44, Göteborg: Göteborg University.

FOLLÉR, M. A. \& HANSSON, L. O., 1996. Human Ecology and Health. Adaptation to a Changing World. Göteborg: Göteborg University.

FORD, J., 1971. The Role of the Trypanosomiases in African Ecology: A Study of the Tsetse Fly Problem. Oxford: Claredon Press.

HAINES, A.; EPSTEIN, P. R. \& McMICHAEL, A. J., 1994. Global health watch: Monitoring impacts of environmental change. In: Health and Climate Change (D. Sharp, ed.), pp. 31-36, London: The Lancet.

KINGSNORTH, P., 1999. Human health on the line. The Ecologist, 29:92-94.

LAST, J. M., 1998. Public Health and Human Ecology. 2nd Ed. Stanford: Appleton \& Lange.

LITTLE, M., 1998. Assignments of meaning in epidemiology. Social Science and Medicine, 47:1135-1145.
MARMOT, M., 1998. Improvement of social environment to improve health. Lancet, 351:57-60.

MARTENS, P., 1998. Health and Climate Change. London: Earthscan.

MARTENS, W. J. M.; JETTEN, T. H.; ROTMANS, J. \& NIESSEN, L. W., 1995. Climate change and vectorborne diseases. A global modelling perspective. Global Environmental Change, 5:195-209.

McMICHAEL, A. J., 1995. Planetary Overload. Global Environmental Change and the Health of the Human Species. Cambridge: Cambridge University Press.

McMICHAEL, A. J.; BOLIN, B.; COSTANZA, R.; DAILY, G. C.; FOLKE, C.; LINDAHL-KIESSLING, K.; LINDGREN, E. \& NIKLASSON, B., 1999. Globalisation and the sustainability of human health. An ecological perspective. BioScience, 49:205-210.

NEWSON, L. A., 1998. A historical-ecological perspective on epidemic disease. In: Advances in Historical Ecology (W. Balée, ed.), pp. 42-63, New York: Columbia University Press.

NICHOLLS, N., 1994. El Niño-Southern Oscillation and vector-borne disease. In: Health and Climate Change (D. Sharp, ed.), pp. 21-23, London: The Lancet.

NUSSBAUM, M. C., 1997. Cultivating Humanity. A Classical Defense of Reform in Liberal Education. Cambridge: Harvard University Press.

NYGREN, A., 1999. Local knowledge in the environment-development discourse. From dichotomies to situated knowledges. Critique of Anthropology, 19:267-288.

PARRY, M. L. \& ROSENZWEIG, C., 1994. Food supply and risk of hunger. In: Health and Climate Change (D. Sharp, ed.), pp. 23-25, London: The Lancet.

PEARCE, F, 1999. Health crisis. New Scientist, 164:33.

RICHARDS, P., 1985. Indigenous Agricultural Revolution: Ecology and Food Production in West Africa. London: Hutchinson.

ROGERS, D. J. \& PACKER, M. J., 1994. Vector-borne diseases, models, and global change. In: Health and Climate Change (D. Sharp, ed.), pp. 19-21, London: Lancet.

RUTTAN, V. W.; BELL, D. E. \& CLARK, W. C., 1994. Climate change and food security. Agriculture, health and environmental research. Global Environmental Change, 4:63-77.

SCHMIDT, K., 1997. Testing the waters. New Scientist, 15:46.

SNOW, C. P., 1969. The Two Cultures and a Second Look. Cambridge: Cambridge University Press.

UN (United Nations), 1992. Agenda 21: Programme of Action for Sustainable Development. Geneva: United Nations.

WALTNER-TOEWS, D., 1999. An Ecosystem Approach to Human Health and Infectious Diseases. IDRC/ CRDI:CIID International Workshop, Rio de Janeiro, Brazil, 7-12 November 1999. <http:// www. idrc. $\mathrm{ca} / \mathrm{lacro} / \mathrm{docs} /$ conferencias/ecosaluddoc2. Html>.

WATTS, S., 1997. Epidemics and History, Disease, Power and Imperialism. New Haven: Yale University Press.

WCED (World Commission on Environment and Development), 1987. Our Common Future (The Brundtland Report). Oxford/New York: Oxford University Press.

WDR (World Disaster Report), 1998. World Disaster Report, International Federation of Red Cross and Red Crescent Societies. New York: Oxford University Press. 